Check for updates

Cite this: RSC Adv., 2017, 7, 40849

\title{
Self-assembled star-shaped chiroplasmonic gold nanoparticles for an ultrasensitive chiro- immunosensor for viruses $\uparrow$
}

\begin{abstract}
Syed Rahin Ahmed, ${ }^{a}$ Éva Nagy ${ }^{\mathrm{b}}$ and Suresh Neethirajan (D) *a
Near field optics and optical tunneling light-matter interactions in the superstructure of chiral nanostructures and semiconductor quantum dots exhibit strong optical rotation activity that may open a new window for chiral-based bioanalyte detection. Herein we report an ultrasensitive, chiroimmunosensor using a superstructure of chiral gold nanohybrids (CAu NPs) and quantum dots (QDs). Self-assembly techniques were employed to create asymmetric plasmonic chiral nanostructures to extend the spectral range of the circular dichroism (CD) response to obtain superior plasmonic resonant coupling with the QD excited state; this may help to achieve lower limit of detection (LOD) values. As a result, the designed probe could detect avian influenza A (H5N1) viral concentrations at the picomolar level, a significant improvement in sensitivity in comparison to a non-assembled CAu NP-based chiroassay. The practicability of the proposed sensing system was successfully demonstrated on several virus cultures, including avian influenza A (H4N6) virus, fowl adenovirus and coronavirus in blood samples. The results of our study highlight that exciton-plasmon interactions change the chirality, and the use of selfassembled nanostructures is an efficient strategy for enhancing the sensitivity of plasmonic nanosensors.
\end{abstract}

Received 28th June 2017

Accepted 7th August 2017

DOI: $10.1039 / c 7 r a 07175 b$

rsc.li/rsc-advances chiroptics. The field of nano-chiroptics is a new emerging and exciting frontier. The popularity of nano-chiroptics has exploded because of novel ways to fabricate engineered metallic nanostructures with a tunable surface morphology and achieve their nano-assembly, which offers unprecedented control over their electronic and optical properties. ${ }^{7}$ Undoubtedly, lightmatter interactions in chiral plasmonic metal-semiconductor nanohybrid structures will introduce a new field in the sub-field of physical optics. The most significant advantage of such nanohybrid structures is that they enhance the chiroptical response, which could be of great interest in a variety of applications related to chiral biosensing, opening up new areas of research. ${ }^{8}$ In comparison to natural chiral molecules, chiral plasmonic nanostructures not only lead to large chiroptical effects, but also introduce entirely new concepts of superchiral light in technological applications. ${ }^{9-11}$

In the present study, we assumed that the nano-assembly of CAu NPs and QDs through an immune-reaction could be used for bioanalytical purposes, where the chiro-optical properties would be modified by a light-matter interaction. Previously, chiro-optical detection techniques were developed based on the assembly of a chiral plasmonic nanoparticles connected by antigen-antibody bridges, and unexpectedly chirality was created due to either the homo-plasmonic nanoparticles or the twisting of the hetero-plasmonic nanoparticles, thus achieving exceptionally low LODs. ${ }^{\mathbf{1 2 - 1 5}}$ Several other methods for the nanoassembly of plasmonic nanoparticles to generate circular dichroism based on DNA origami, ${ }^{16,17}$ silica nanohelices as

${ }^{a}$ BioNano Laboratory, School of Engineering, University of Guelph, Guelph, Ontario,
Canada N1G 2W1. E-mail: sneethir@uoguelph.ca
${ }^{b}$ Department of Pathobiology, Ontario Veterinary College, University of Guelph,
Guelph, ON N1G 2 W1, Canada
$\begin{aligned} & \dagger \text { Electronic supplementary information } \quad \text { (ESI) available. See DOI: } \\ & \text { 10.1039/c7ra07175b }\end{aligned}$

\section{Introduction} nanoplasmonics. ${ }^{\mathbf{1 - 6}}$

and experimental investigations on nanoplasmonics in near field optics, with only a few studies dealing with nano- 
chiral templates,${ }^{\mathbf{1 8}}$ the polymerase chain reaction, ${ }^{19}$ DNA scaffolds $^{20}$ and specific non-covalent interactions ${ }^{21}$ have been reported. In addition, a broad understanding of plasmonic structures for enhancing the chiroptical response has been acquired both theoretically and experimentally. ${ }^{22}$ Herein, our approach is to enhance the chiro-optical properties of CAu NPs by nano-assembly with QDs through antibody-antigen interactions.

Nano-assemblies of chiral plasmonic nanoparticles with QDs may play a fundamental role in an entirely new class of nanohybrids with optical resonances through both the near field and far-field coupling mechanisms and with enhanced chiroptical effects. ${ }^{7}$ Plasmonic nanostructures could play a vital role in achieving an excellent chiro-optical enhancement from metal semiconductor nanohybrids, as well as lower LODs for biosensing applications. In particular, the plasmonic morphological alteration of nanostructure surfaces allows the tailoring of surface plasmon resonances and hence their interaction with incident light. Another important component is maximizing the overlap of the absorption and emission spectra of the CAu NPs and QDs, respectively. Considering the above factors, we have developed a self-assembled star-shaped chiro-plasmonic nanostructure using $\mathrm{L}(+)$-ascorbic acid as a key material. We have demonstrated the utility of this nanostructure by using it in a chiro-immunosensor for avian influenza virus A (H5N1), targeting the hemagglutinin (HA) and neuraminidase (NA) surface proteins on the virus.

We chose influenza virus A (H5N1) detection as a model analyte because of its high pathogenicity in poultry and poultry consumers. The H5N1 flu strain is of great concern globally due to its high mortality rate and continuously expanding host range, and the potential for the emergence of pandemic diseases. Highly pathogenic avian influenza viruses do not readily transfer between humans; however, the disease can be transmitted from infected domestic poultry to humans via close contact interactions (i.e., interaction with infected feces). The effects of $\mathrm{H} 5 \mathrm{~N} 1$ can also be felt on a global economic level, as pandemic infections cause large economic losses. Therefore, a rapid and sensitive detection tool for the identification of influenza viruses is crucial for early detection and timely responses to overcome the pandemic threat. ${ }^{23-26}$

In North America, fowl adenoviruses (FAdVs) are responsible for several diseases in chickens, namely hepatitis, hydropericardium syndrome, respiratory disease and tenosynovitis, causing significant losses to the poultry industry worldwide every year. An early detection system with high sensitivity and specificity is urgently needed to prevent the spread of diseases in the poultry sector. ${ }^{27}$ Infectious bronchitis (IB), a coronavirus, is another important disease in chickens caused by IB virus (IBV), which is one of the primary agents of respiratory disease in chickens worldwide. Chickens infected with IBV exhibit the symptoms of gasping, coughing, rales, and nasal discharge, huddling together, and appearing depressed as well as wet droppings and increased water consumption. ${ }^{28}$

To demonstrate the real-world applications of the proposed chiro-optical sensor, avian influenza A (H4N6), the fowl adenoviruses-9 (FAdVs-9) strain and infectious bronchitis virus (IBV) were chosen as bioanalyte target candidates in this study.

\section{Experimental section}

\subsection{Materials and reagents}

Gold(III) chloride trihydrate $\left(\mathrm{HAuCl}_{4} \cdot 3 \mathrm{H}_{2} \mathrm{O}\right)$, cetyltrimethylammonium bromide (CTAB), 3,3',5,5'-tetramethylbenzidine (TMB), hydrogen peroxide $\left(\mathrm{H}_{2} \mathrm{O}_{2}\right)$, poly-L-lysine (PLL), Nunc-Immuno 96-well plates, CdTe QDs (emission wavelength $710 \mathrm{~nm}$ ), and bovine serum albumin (lyophilized powder, $\geq 96 \%$ ) were purchased from Sigma-Aldrich (St. Louis, MO, USA). The anti-influenza A (H5N1) virus hemagglutinin (HA) antibody [2B7] (ab135382, lot: GR100708-16), recombinant influenza virus A (Avian/Vietnam/1203/04) (H5N1) (lot: GR301823-1), goat antimouse IgG, horseradish peroxidase (HRP)-conjugated whole antibody (Ab 97023, lot: GR 250300-11) and immunoassay blocking buffer (Ab 171534, lot: GR 223418-1) were purchased from Abcam, Inc. (Cambridge, UK). Recombinant influenza virus A (H1N1) (California) (CLIHA014-2; lot: 813PH1N1CA) was purchased from Cedarlane (Ontario, Canada). Influenza A (H5N2) hemagglutinin antibodies (Anti-H3N2 antibodies HA MAb, lot: HB05AP2609), influenza A (H7N9) hemagglutinin antibodies (Anti-H7N9 antibody HA MAb, lot: HB05JA1903), recombinant influenza virus A (H5N2) HA1 (A/Ostrich/South Africa/A/109/2006)(lot: LC09AP1021), recombinant influenza virus A (H7N8) HA1 (A/Mallard/Netherlands/33/2006) (lot: LC09AP1323) and recombinant influenza virus A (H7N9) HA1 (A/Shanghai/1/2013) (lot: LC09JA2702) were purchased from Sino Biological, Inc. (Beijing, China). Avian influenza H5N1 neuraminidase polyclonal antibody (Cat. PA5-34949) was received from Invitrogen (Ontario, Canada). Anti-H4 (A/environment/ Maryland/1101/06) (H4N6) polyclonal antibody was purchased from MyBioSource Inc., San Diego, USA. Chicken whole blood (Cat. no. IR1-080N) was received from Innovation Research, Michigan, USA. The chicken hepatoma cell line (CH-SAH) was kindly provided by Solvay Animal Health (Mendota Heights, MN, USA). Embryonated eggs were received from the Animal Disease Research Institute, Canadian Food Inspection Agency (Ottawa, Ontario, Canada). All experiments were performed using highly pure deionized (DI) water $(>18 \mathrm{M} \Omega \mathrm{cm})$.

\subsection{Preparation of different shaped CAu NPs}

Chiral gold nanoparticles (CAu NPs) with different shapes were prepared by varying the $\mathrm{L}(+)$-ascorbic acid concentration. $20 \mu \mathrm{L}$ of various concentrations of $\mathrm{L}(+)$-ascorbic acid $(0.1,0.05,0.01, \&$ $0.005 \mathrm{M}$ ) was mixed with $1 \mathrm{~mL}$ of $20 \mathrm{mM}$ aqueous $\mathrm{HAuCl}_{4}$ solution separately under vigorous stirring at $25{ }^{\circ} \mathrm{C}$. Color appeared within a few seconds based on the $\mathrm{L}(+)$-ascorbic acid concentration indicating nanoparticle formation. Here, $\mathrm{L}(+)$ ascorbic acid acts as both a reducing agent and a stabilizer, as well as a chiral ligand for the CAu NPs.

\subsection{Preparation of self-assembled chiral gold nanostructures}

Self-assembled structures of CAu NPs were prepared as previously reported with slight modification. ${ }^{12}$ For example, $10 \mathrm{~mL}$ of 
$2.5 \times 10^{-4} \mathrm{M} \mathrm{HAuCl}_{4}$ and $0.05 \mathrm{M} \mathrm{CTAB}$ were mixed and gently stirred for $10 \mathrm{~min}$. Then a $0.01 \mathrm{M}(50 \mu \mathrm{L})$ solution of $\mathrm{L}(+)-$ ascorbic acid was added to the mixture followed by the addition of $20 \mu \mathrm{L}$ of $\mathrm{AgNO}_{3}(0.01 \mathrm{M})$ solution. The self-assembled nanostructures were separated from the solution by centrifugation at $2000 \mathrm{rpm}$ for $10 \mathrm{~min}$, and were redispersed in $1 \mathrm{~mL}$ of water.

\subsection{Avian influenza A H4N6 virus culture}

Low pathogenic avian influenza virus A H4N6 (Avian influenza virus A/Duck/Czech/56 (H4N6)) was propagated in 11 day-old embryonated chicken eggs by inoculation into the allantoic cavity. ${ }^{29}$ The virus titer in the allantoic fluid was determined at $72 \mathrm{~h}$ post-inoculation and expressed as the $50 \%$ tissue culture infective dose of $128 \mathrm{HAU} / 50 \mu \mathrm{L}$. Unit conversion from HAU to PFU is a very rough estimate and depends on the sensitivity of the viral strain, the cell types used in the infectivity assay, and also the parameters associated with the culturing of the virus stock. The approximate conversion factors are $1 \mathrm{HAU} \approx 1 \times 10^{5}$ PFU and $10^{6} \mathrm{EID} / 50 \mathrm{~mL} \approx 0.7 \times 10^{6} \mathrm{PFU} \mathrm{mL}{ }^{-1}$, where PFU is the virus titer (virus per $\mathrm{mL}$ ) or the plaque forming units, EID is the egg infective dose and HAU is hemagglutinin units. EID $_{50}$ (50\% egg lethal dose) is a common concentration unit for AIV and $128 \mathrm{HAU} / 50 \mu \mathrm{L}$ is equal to $1 \times 10^{6.2} \mathrm{EID}_{50}$ per $\mathrm{mL}^{38}$

\subsection{Fowl adenoviruses-9 (FAdVs-9) virus culture}

The FAdV-9 strain was propagated in chicken hepatoma cells (CH-SAH cell line) as described previously. ${ }^{30} \mathrm{CH}-\mathrm{SAH}$ cells were grown to confluency at $37{ }^{\circ} \mathrm{C}$ with $5 \% \mathrm{CO}_{2}$ in Dulbecco's modified Eagle's medium/nutrient mixture F-12 Ham with $10 \%$ non-heat-inactivated fetal bovine serum as described previously. After infection with the virus, the cells were fed with maintenance medium of D-MEM/F-12 with all the additions, except that the FBS concentration was reduced to $5 \%$. The FAdV-9 viral titer in allantoic fluid was determined to be $5 \times 10^{7}$ PFU $\mathrm{mL}^{-1}$.

\subsection{Infectious bronchitis virus (IBV) culture}

The viruses were propagated and titrated as previously described. ${ }^{31,32}$ The procedures were carried out in specific pathogen free (SPF) embryonated eggs and the titers were determined by the method of Reed and Muench. ${ }^{33}$ The viral titer of the stock solution was $1 \times 10^{6} \mathrm{EID}_{50}$ per $\mathrm{mL}$.

\subsection{Specificity of antibodies towards target influenza A} (H5N1) virus

The conventional ELISA method was used to determine the specificity of the anti-H5N1 HA (Ab 135382) for influenza virus A/Vietnam 1203/04/2009 (H3N2). A total of $50 \mu \mathrm{L}\left(1 \mu \mathrm{g} \mathrm{mL}{ }^{-1}\right)$ of virus solution in PBS buffer ( $\mathrm{pH}$ 7.5) was added to a PS plate and kept overnight at $4{ }^{\circ} \mathrm{C}$. The next day, the wells were rinsed three times with PBS buffer ( $\mathrm{pH}$ 7.5), then immunoassay blocking buffer $(\mathrm{Ab} 171534,100 \mu \mathrm{L})$ was added and the plates were kept at room temperature for $2 \mathrm{~h}$. After rinsing three times with PBS buffer (pH 7.5) solution, anti-H5N1 HA Ab $\left(1 \mu \mathrm{g} \mathrm{mL}{ }^{-1}\right)$, antiH5N1 NA antibody (1 $\left.\mu \mathrm{g} \mathrm{mL}^{-1}\right)$, anti-H5N2 HA antibody
(1 $\left.\mu \mathrm{g} \mathrm{mL} \mathrm{mL}^{-1}\right)$, and anti-H7N9 HA antibody $\left(1 \mu \mathrm{g} \mathrm{mL}^{-1}\right)$ were added to each of the wells, and the plate was incubated at room temperature for $1 \mathrm{~h}$. Again, it was washed with PBS buffer $(\mathrm{pH}$ 7.5), and HRP-labelled secondary antibody $(50 \mu \mathrm{L}$, $1 \mu \mathrm{g} \mathrm{mL}^{-1}$ ) was added and incubated at room temperature for $1 \mathrm{~h}$. Then unbound or loosely bound secondary antibodies were washed out using PBS buffer ( $\mathrm{pH} 7.5)$, and TMBZ $(10 \mathrm{nM}) / \mathrm{H}_{2} \mathrm{O}_{2}$ (5 $\mathrm{nM})$ solution was added to each well $(50 \mu \mathrm{L}$ per well) for $10 \mathrm{~min}$ at room temperature. The enzymatic reactions were stopped by adding $10 \% \mathrm{H}_{2} \mathrm{SO}_{4}$ solution $(50 \mu \mathrm{L}$ per well), and the absorbance of the solutions was recorded using a microplate reader (Cytation 5, BioTek Instruments Inc., Ontario, Canada) at $450 \mathrm{~nm}$.

\subsection{Anti-H5N1 HA (Ab 135382) conjugation with self- assembled $\mathrm{CAu}$ nanostructures}

The target virus-specific antibodies (anti-H5N1 HA Ab 135382) were bound to self-assembled nanostructures of CAu NPs through electrostatic bonds. $1 \mathrm{~mL}$ of positively charged $(+12.38 \mathrm{eV}) \mathrm{CAu}$ nanostructures was mixed with negatively charged $(-2.31 \mathrm{eV}) \mathrm{HA}$ Ab 135382 antibody $\left(1 \mu \mathrm{L}, 5 \mathrm{ng} \mathrm{mL}^{-1}\right)$ and the mixture was continuously stirred for $2 \mathrm{~h}$ at room temperature. The mixture was then centrifuged (4000 rpm for $10 \mathrm{~min}$ ) and washed 3 times with PBS buffer to remove the unbound components. To check the antibody-nanostructure binding, the samples were blocked with $2 \%$ BSA $(100 \mu \mathrm{L})$ for $2 \mathrm{~h}$ at room temperature. After centrifugation and washing steps, $1 \mathrm{ng} \mathrm{mL}^{-1}(50 \mu \mathrm{L})$ of anti-mouse IgGhorseradish peroxidase (HRP) (Santa Cruz Biotechnology, CA) was added to each well, followed by incubation at room temperature for $1 \mathrm{~h}$. Upon adding a total of $100 \mu \mathrm{L}$ of TMBZ substrate solution $\left(10 \mu \mathrm{g} \mathrm{mL} \mathrm{m}^{-1} \mathrm{TMBZ}, 10 \% \mathrm{H}_{2} \mathrm{O}_{2}\right.$ in $100 \mathrm{mM} \mathrm{NaOAc}$, pH 6.0) to each well for 5-30 $\mathrm{min}$ at $25{ }^{\circ} \mathrm{C}$, the enzymatic reaction resulted in color developing (blue color). The reaction was stopped by adding $10 \% \mathrm{H}_{2} \mathrm{SO}_{4}(100 \mu \mathrm{L})$, and the absorbance was recorded at $450 \mathrm{~nm}$ with a reference at $655 \mathrm{~nm}$.

\subsection{Binding of anti-H5N1 NA with carboxyl-capped QDs using ELISA}

Carboxyl-capped CdTe QDs were bound with antibodies through EDC/NHS chemistry. $1 \mathrm{~mL}$ of QDs was placed in a $1.5 \mathrm{~mL}$ microfuge tube followed by addition of $4 \mathrm{mM}$ EDC, NHS (10 mM) and $1 \mu \mathrm{L}$ of anti-NA antibodies $\left(5 \mathrm{ng} \mathrm{mL}^{-1}\right)$, and the mixture was gently stirred at $10{ }^{\circ} \mathrm{C}$. To confirm the binding between the QDs and antibodies, ELISA was performed as follows: the mixture was centrifuged $(1000 \mathrm{rpm}, 10 \mathrm{~min})$ and washed to remove unbound antibodies or other reagents, and then the conjugated part was blocked with $2 \%$ BSA for $1 \mathrm{~h}$. Antimouse IgG-HRP (Santa Cruz Biotechnol., CA) $\left(50 \mu \mathrm{L}, 1 \mathrm{ng} \mathrm{mL}^{-1}\right)$ was then added to each well after washing steps and the plate was incubated for $1 \mathrm{~h}$ at room temperature. The samples were washed after centrifugation three times, and $50 \mu \mathrm{L}$ of TMBZ substrate solution $\left(10 \mu \mathrm{g} \mathrm{mL}^{-1} \mathrm{TMBZ}, 10 \% \mathrm{H}_{2} \mathrm{O}_{2}\right.$ in $100 \mathrm{mM}$ $\mathrm{NaOAc}, \mathrm{pH}$ 6.0) was added to each well and allowed to stand for 5-30 min at $25{ }^{\circ} \mathrm{C}$. Finally, the reaction was stopped by adding $50 \mu \mathrm{L}$ of $10 \% \mathrm{H}_{2} \mathrm{SO}_{4}$ and the absorbance was recorded at $450 \mathrm{~nm}$. 


\subsection{Chiro-optical detection of influenza virus A (H5N1)}

Chiral-based optical sensing experiments were performed after confirming the binding of anti-H5N1 HA (Ab 135382) with the CAu nanostructures and QDs using the ELISA method. $100 \mu \mathrm{L}$ of anti-HA Ab-conjugated CAu nanostructures containing various concentrations of recombinant influenza A (H5N1) in PBS buffer were added to a CD cuvette. Then, $100 \mu \mathrm{L}$ of anti-NA Abconjugated QDs was added, and the CD response was measured. Other influenza viruses were examined in the same manner as a negative control. The samples were excited at $380 \mathrm{~nm}$, and the excitation and emission slits were $5 \mathrm{~nm}$ and $5 \mathrm{~nm}$, respectively. Based on the chiro-optical response at different concentrations of the target virus, a statistical curve was constructed. In the case of the clinical influenza A (H4N6) virus culture samples, $50 \mu \mathrm{L}$ of anti-HA Ab-conjugated CAu nanostructures containing various concentrations of recombinant influenza A (H4N6) in chicken blood samples were added to a CD cuvette. Then, $100 \mu \mathrm{L}$ of anti-NA Ab-conjugated QDs was added, and the CD response was recorded. A similar sensing method was followed in the case of the fowl adenoviruses-9 (FAdVs-9) strain and infectious bronchitis virus (IBV) detection.

\subsection{Validation with a commercial ELISA kit}

A comparison experiment was performed with the commercial avian influenza A H5N1 ELISA kit (Cat. no. MBS9324259, MyBioSource, Inc., San Diego, USA) to validate our proposed method. Different concentrations of virus solution were prepared using a sample diluent that was received with the commercial ELISA kit strictly maintaining the manufacturer's protocol during the bioassay. The color developed with a different absorbance intensity related to the viral concentration in the 96-well plates was recorded at $450 \mathrm{~nm}$. Influenza A (H4N6) virus detection was also validated with a commercially available ELISA kit (Cat. no. NS-E10156, Novatein Biosciences, Woburn, USA). The assay procedure was strictly followed as mentioned in the protocol manual.

\subsection{Spectroscopy and structural characterization}

Transmission electron microscopy (TEM) images were captured using a Tecnai TEM (FEI Tecnai G2 F20, Ontario, Canada). Zeta potential was measured with a Zetasizer Nano ZS (Malvern Instruments Ltd., Worcestershire, UK). Circular dichroism spectra were recorded using a JASCO CD Spectrometer (model: J-815, Easton, USA).

\section{Results \& discussion}

Artificial chiral plasmonic nanomaterials demonstrate extraordinary rotational ability of polarizing light by engineering intraparticle couplings with light-emitting nanomaterials at a nanoscale gap in comparison to naturally occurring chiral materials. This concept was utilized in our study to develop a chiroimmunosensor that employs the exciton-plasmon interaction in chiral gold nanoparticle (CAu NP)-CdTe QD nanohybrids. Two different anti-influenza virus surface protein antibodies, named anti-HA and anti-NA, were bound to the CAu NPs and
QDs, respectively. Then, a nano-sandwich structure was formed with the addition of target influenza virus A/Vietnam 1203/04/ 2009 (H3N2). The amount of CAu NPs and QDs taking part in the nano-assembly process in total depends on the viral concentration. Hence, chiro-optical changes would be influenced by the CAu NP-QD nanohybrids. With our proposed sensing concept, it is reasonable to move to a chiro-plasmonic rough surface that has more light scattering properties, as well as confined energy in space, and enables the creation of a strong coupling regime and increased optical non-linearities through light-matter interactions with the QDs. ${ }^{\mathbf{1} 34}$ Such strong localization of energy in the nanoscale gap may provide specific spatial positions to tune and further enhance the chiral properties of the CAu NPs efficiently.

In order to fully exploit the nanostructured morphology, a series of differently shaped (hetero-structured) CAu NPs were prepared by varying the $\mathrm{L}(+)$-ascorbic acid concentration during the reaction process. As shown in Fig. 1, different sizes and morphologies of CAu NPs were obtained by using various concentrations of $\mathrm{L}(+)$-ascorbic acid in $20 \mathrm{mM} \mathrm{HAuCl}_{4}$ solution. Prolate-shaped CAu NPs were obtained with a diameter of $50 \mathrm{~nm}$ at $0.1 \mathrm{M} \mathrm{L}(+)$-ascorbic acid (Fig. 1A). As the concentration of $\mathrm{L}(+)$-ascorbic acid shifted from $0.1 \mathrm{M}$ to $0.005 \mathrm{M}$ (Fig. 1A-D), the CAu NP structures ranged from well-defined simple flower-like shapes (Fig. 1B), to urchin (Fig. 1C), and dendritic-type morphologies (Fig. 1D). It should be noted that urchin-shaped CAu NPs with many spikes were obtained when the concentration of $\mathrm{L}(+)$-ascorbic acid was $0.01 \mathrm{M}$ (Fig. 1C). Unfortunately, although the dendritic-shaped CAu NPs contained many arms and branches in their structural morphology, spectroscopic study showed a very weak plasmonic peak (Fig. 2). The plasmonic peaks obtained from the prolate, flower, and urchin-shaped CAu NPs were located at $548 \mathrm{~nm}, 565 \mathrm{~nm}$, and $590 \mathrm{~nm}$, respectively. Among them, the urchin-shaped CAu NPs were chosen for further experiments due to the numerous spikes on their surfaces, as well as their broadened plasmonic peak, which offers the possibility of having maximum overlap and coupling with the excitonic wavelength of the QDs, which may strengthen the optical activity.

Enhanced localized surface plasmon resonance (LSPR) could potentially serve as an effective platform to prove that the hetero-structured nanoparticles have enough sensitivity for bioanalytical detection. ${ }^{35}$ With this concept in mind, selfassembled structures of star-shaped nanoparticles were prepared by the addition of CTAB, which served as a 'glue' to link the $\{100\}$ facets of two adjacent CAu NPs, which in turn aided in organizing the chiral gold nanostructures into short chains. $^{36}$ The star-shaped CAu nanostructures with various morphologies are shown in Fig. 4, with a spike length and diameter of $10 \mathrm{~nm}$ and $2 \mathrm{~nm}$, respectively (Fig. 3F).

CdTe NPs were chosen to make nanohybrids with the CAu NPs due to their strong emission properties and the energy overlap possibility between the excitonic and plasmonic states of the resulting nanohybrids. The photoluminescence spectra (PL) and ultra-violet (UV) spectra of the QDs are shown in Fig. S1A; $\uparrow$ the emission peak was located at $710 \mathrm{~nm}$. The particle 

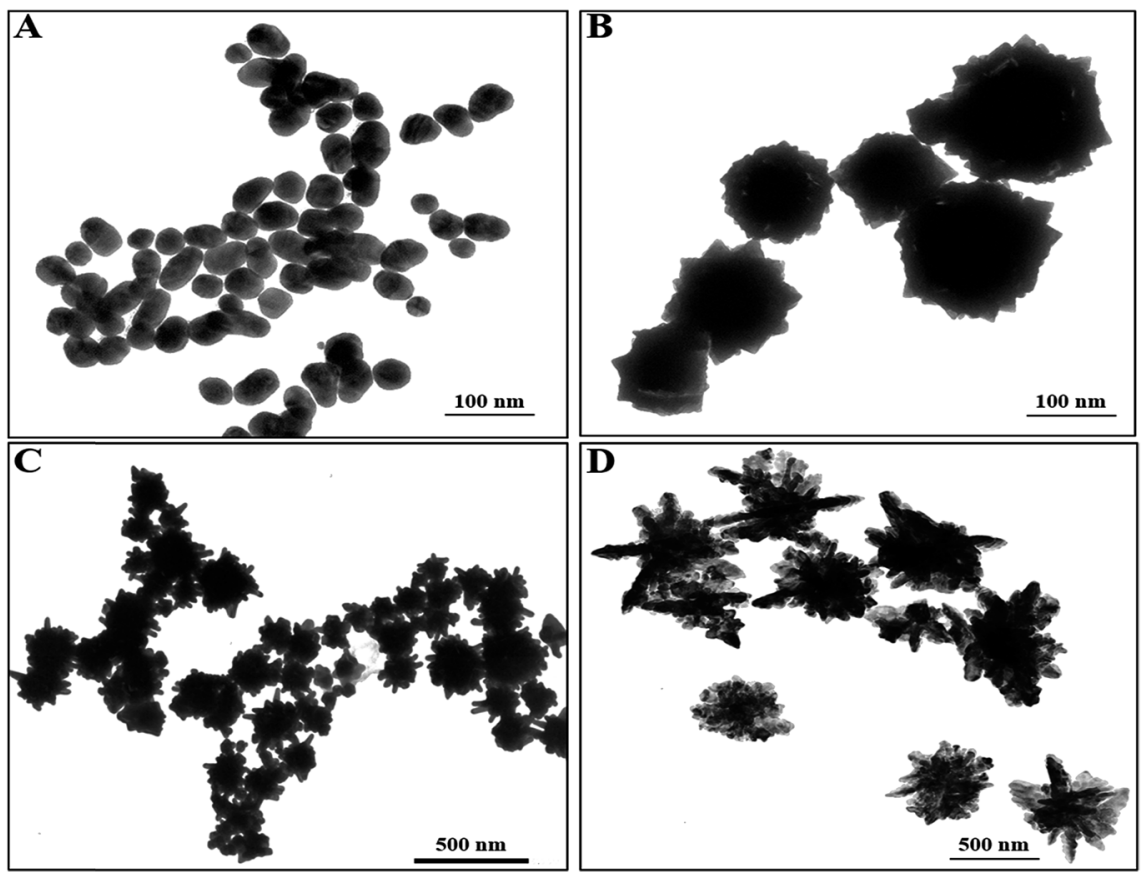

Fig. 1 Transmission electron microscopy images of the developed CAu NPs; (A) prolate-like, (B) flower-like, (C) urchin-like 8 (D) dendriticshaped CAu NPs.

size and concentration were $6.5 \mathrm{~nm}$ and $3.7 \times 10^{-7} \mathrm{M}$, respectively, calculated based on the Peng equation. ${ }^{37}$

The specificity of anti-influenza A (H5N1) virus hemagglutinin (HA) antibody Ab 135382 against recombinant influenza virus A (Avian/Vietnam/1203/04) (H5N1) was confirmed using a conventional ELISA method. Fig. S1B $\uparrow$ shows that the optical density obtained due to the enzymatic activity of the target virus/Ab 135382 HA/HRP-conjugated secondary antibody/ TMBZ- $\mathrm{H}_{2} \mathrm{O}_{2}$ complex and the target virus/anti-H5N1 NA/HRPconjugated secondary antibody/TMBZ $-\mathrm{H}_{2} \mathrm{O}_{2}$ complex was higher than that with anti-H5N2 HA and anti-H7N9 HA Ab, implying the specificity of $\mathrm{Ab} 135382$ towards recombinant influenza virus A (Avian/Vietnam/1203/04) (H5N1). The higher

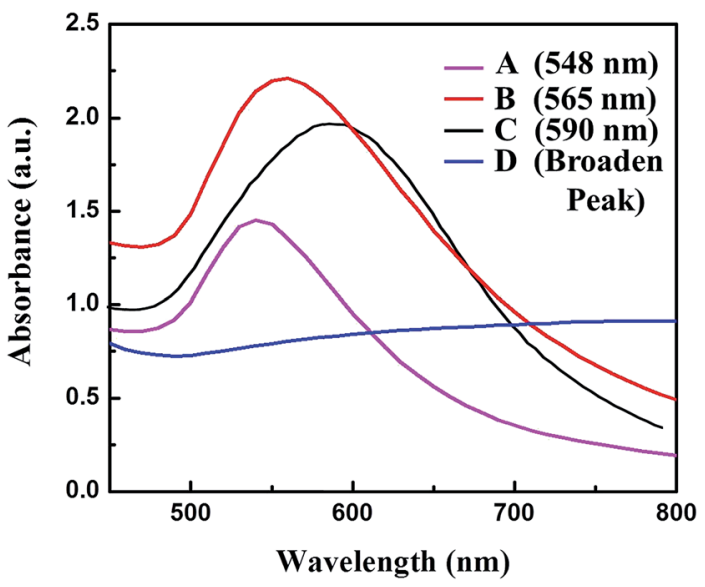

Fig. 2 UV-visible spectra of differently shaped CAu NPs; (A) prolatelike, (B) flower-like, (C) urchin-like \& (D) dendritic-shaped CAu NPs. optical density obtained for the anti-H5N1 Ab 135382 and CAu nanostructure complex in the ELISA results confirmed the successful binding between anti-H5N1 Ab 135382 and the CAu nanostructures (Fig. S2A $\dagger$ ).

The binding between anti-H5N1 Ab 135382 and the CdTe QDs was confirmed by FTIR spectroscopy. As shown in Fig. S2B, $\uparrow$ the FTIR bands found at $3500-3700 \mathrm{~cm}^{-1}$ for amide $\mathrm{N}-\mathrm{H}$ stretching represent the chemical binding between $\mathrm{Ab}$ 135382 and the CdTe QDs, whereas only carboxylic acid O-H stretching bands appeared for the CdTe QDs alone. The influence of the structural morphology on the sensitivity of the chirosensor was further investigated to enable the selection of the optimized shape of the CAu NPs for the bioassay platforms. Four typical CAu NP structures, prolate-shaped CAu NPs, flowershaped CAu NPs, spiky-like CAu NPs and dendritic-shaped CAu NPs, were selected to construct nanohybrids with QDs through immune-reaction for a chiral biosensor for avian influenza virus detection. It was found that the optical response of the biosensors was largely dependent on the total amount of analyte assembled on these CAu NPs. As shown in Fig. 4, the linear detection ranges of the CAu NPs were drastically influenced by the shape of the nanostructures. The detection range of the urchin-like CAu NPs was $10 \mathrm{pg}$ to $10 \mu \mathrm{g} \mathrm{mL} \mathrm{m}^{-1}$, whereas for the prolate and flower-shaped CAu NPs, the range was between $1 \mathrm{ng}$ and $10 \mu \mathrm{g} \mathrm{mL} \mathrm{m}^{-1}$.

The experimental results revealed that the chiro-optical response from the dendritic-shaped CAu NPs was not significant, probably due to the weak plasmonic peak. In general, rough nanostructures have a higher analyte capture efficiency in bioassay applications than smooth nanostructures, and this ultimately influences the detection limit of the biosensor. 


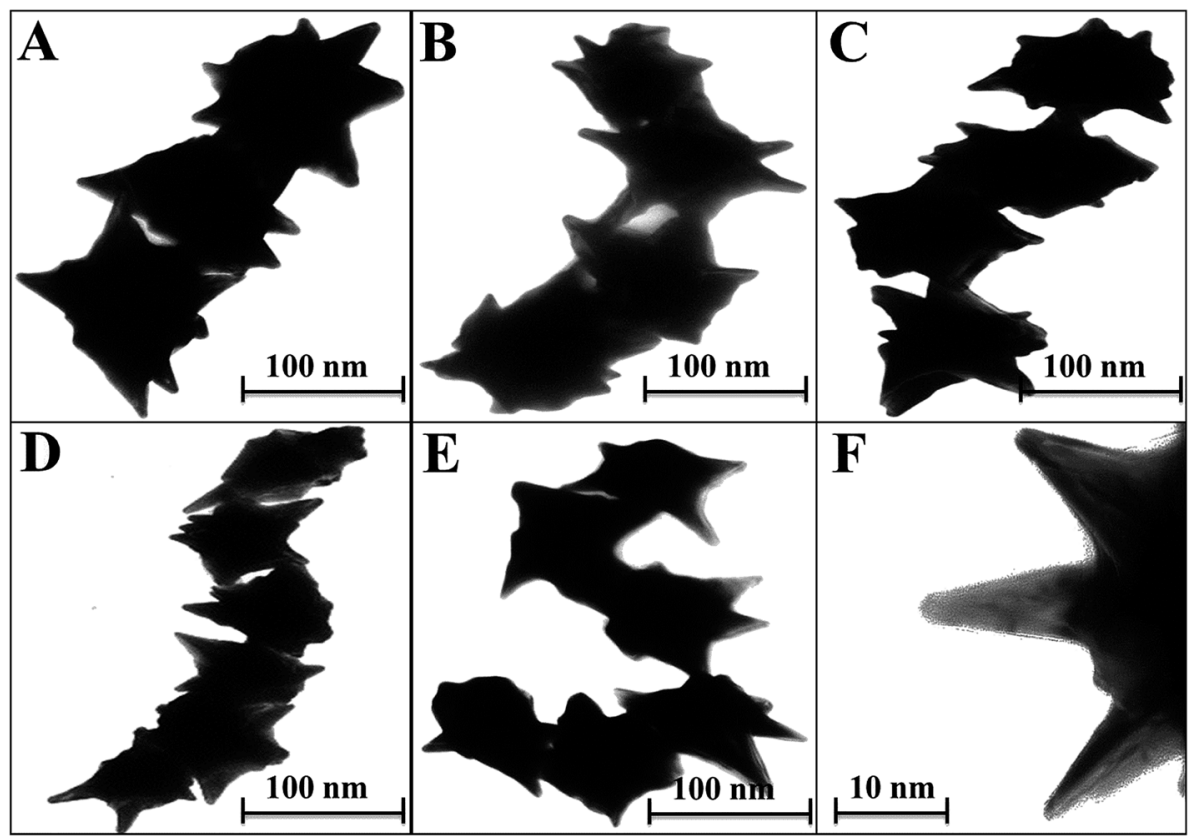

Fig. 3 Transmission electron microscopy images of the self-assembled chiro-plasmonic nanostructures; (A) a short straight chain, (B) a leftturned chain, (C) a right-turned chain, (D) a long chain with a short-angled curve, (E) a long chain with a high-angled curve $\&(F)$ a close-up image of the spikes of a CAu NP.

Compared with the other CAu NPs, the urchin-shaped nanostructures possessed a higher surface to volume ratio, as well as a stronger plasmonic peak; therefore, we chose the urchinshaped CAu NPs to construct the self-assembled chiroplasmonic nanostructures.

Nano-sandwich assembly was achieved via the addition of various concentrations of recombinant influenza virus A (H5N1) to antibody conjugated self-assembled CAu nanostructure and QD solutions. The chiro-optical responses and plasmonic responses with different viral concentrations were carefully examined (Fig. 5A and B), and a calibration curve for the chiro-optical detection of avian influenza virus was constructed. The sensitivity of the bioassay was found to be up to $1 \mathrm{pg} \mathrm{mL}^{-1}$ (Fig. 5C), 10 times more sensitive than the nonassembled urchin-like CAu NPs. Most probably, the repeated scattering of the incident light on the rough plasmonic surface confined a lot of energy in the space, which ultimately influenced the chirality of the CAu nanostructures. A plasmonbased bioassay was performed using the same standard viral concentrations, but the plasmonic response did not significantly correlate with the viral concentration. In the case of the conventional ELISA method, the sensitivity was found to be 1 $\mathrm{ng} \mathrm{mL}^{-1}$.

A selectivity test of the proposed bioassay was implemented with other virus strains, namely H1N1, H5N2, H7N8 and H7N9; a significant chiro-optical response (8-9-fold higher) was only obtained with the target avian influenza virus A (H5N1) in comparison to the others, revealing that the current bioassay is sufficiently selective for the detection of target avian influenza virus A (H5N1) (Fig. 5D). The sensitivity of the developed chirooptical sensor was validated using a commercial colorimetric detection kit for avian influenza A (H5N1) (Table 1 and Fig. S3†). The visual color response of the commercial kit was evident at concentrations of up to $1 \mathrm{ng} \mathrm{mL}{ }^{-1}$, indicating that the chirooptical response-based bioassay is more sensitive than the commercial kit.

We also explored the practical application of the developed chirosensor in PBS buffer and in chicken blood samples for influenza A (H4N6) virus detection, which represents a complex biological mixture. The detection of the avian influenza $\mathrm{A}$ (H4N6) virus concentration is dependent on the amount of CAu nanostructures and QDs present in the nano-assembled structures, and hence is directly associated with the optical activity of

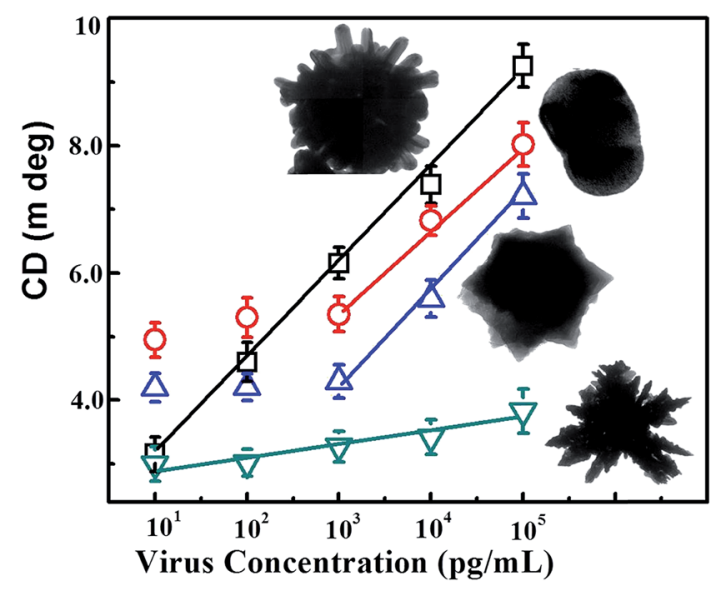

Fig. 4 Comparison of the detection performance of the differently shaped CAu NPs; CD spectrum vs. target virus sensing results. 

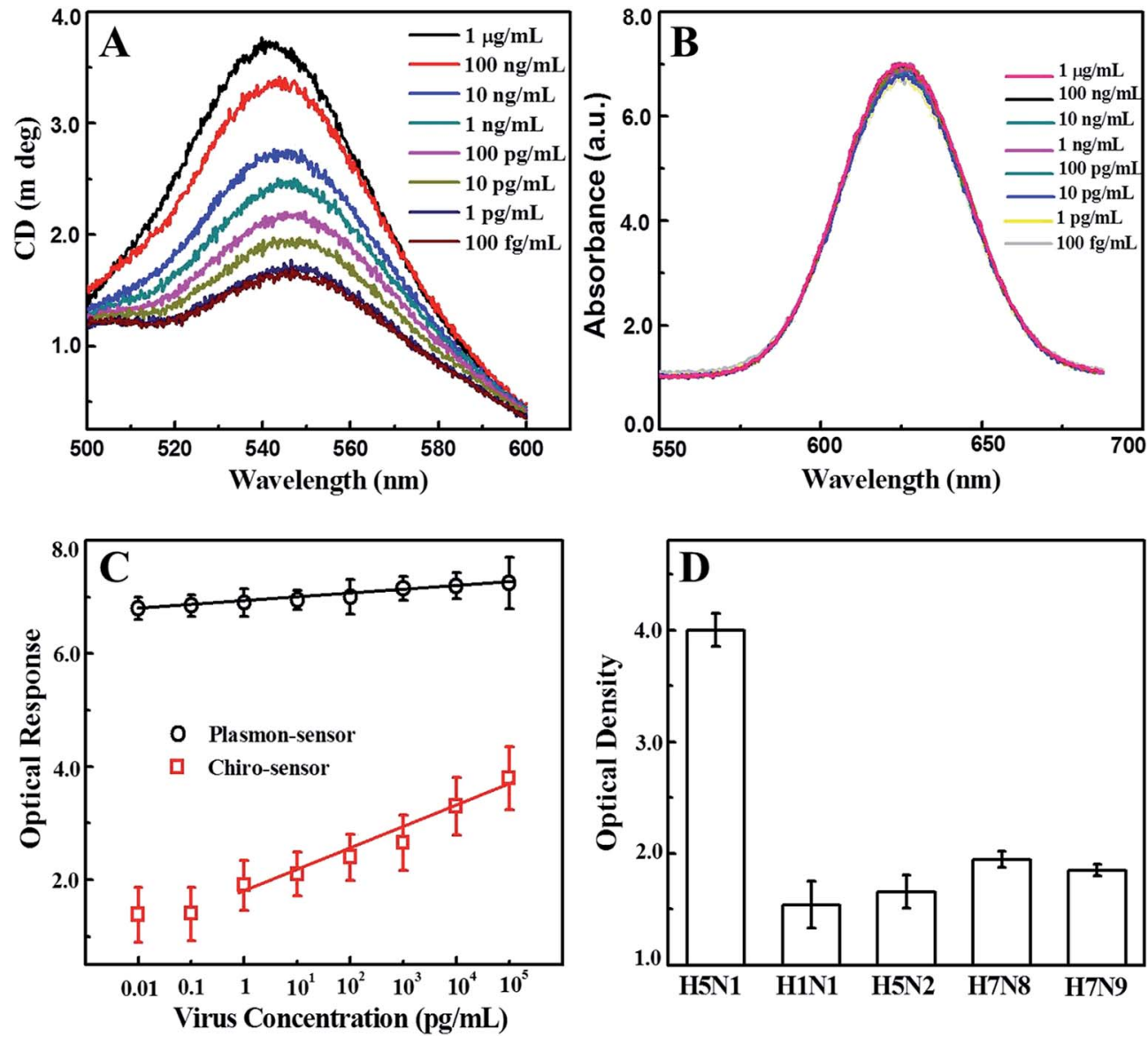

Fig. 5 Detection of the avian influenza virus; (A) the chiro-optical spectra for the detection of different concentrations of the virus, (B) the plasmonic spectra for the detection of different concentrations of the virus, (C) the analytical calibration curves relating the intensity of circular dichroism (CD) and the plasmonic spectra, and (D) the selectivity of the proposed bioassay.

the resulting dispersions. Upon confirming the anti-H4N6 antibody specificity towards the real avian influenza A (H4N6) virus (Fig. S4 $\dagger$ ) and its binding with the CAu nanostructured and QDs (Fig. S5 $†$ ), a calibration curve for the chiroplasmonic detection of influenza A (H4N6) virus was obtained by the standard dilution method (Fig. 6A). The linear range of the influenza A (H4N6) virus detection in PBS buffer was found to be from 100 to $0.01 \mathrm{HAU} / 50 \mu \mathrm{L}$ with a limit of detection of $0.0268 \mathrm{HAU} / 50 \mu \mathrm{L}$. The proposed chirosensor exhibited detection ability in complex media with a linear range of 100 to $0.01 \mathrm{HAU} / 50 \mu \mathrm{L}$; the limit of detection was $0.0315 \mathrm{HAU} / 50 \mu \mathrm{L}$ calculated by the standard deviation

Table 1 Comparison of avian influenza virus A (Avian/Vietnam/1203/ 04) (H5N1) detection using different methods

\begin{tabular}{llllllllllll}
\hline & \multicolumn{1}{c}{ Virus concentration $\left(\mathrm{pg} \mathrm{mL}^{-1}\right)$} \\
\cline { 2 - 9 } Detection method & $10^{7}$ & $10^{6}$ & $10^{5}$ & $10^{4}$ & $10^{3}$ & $10^{2}$ & 10 & 1 & 0 \\
\hline This study & + & + & + & + & + & + & + & + & - \\
Conventional ELISA & + & + & + & + & + & - & - & - & - \\
Commercial kit & + & + & + & + & + & - & - & - & -
\end{tabular}

method. Here, bovine serum albumin (BSA) and influenza virus A (H5N1) were used a control. The validated ELISA results confirmed the superiority of the proposed technique in terms of sensitivity over the commercial kit (Table S1†). FAdVs-9 viruses in blood samples were detected followed by confirming the successful binding of the anti-FAdVs antibody through the ELISA method (Fig. S6†). The sensitivity of the chiral response-based bioassay for FAdVs-9 detection was found to be up to $50 \mathrm{PFU} \mathrm{mL} \mathrm{m}^{-1}$ with a limit of detection of $33.64 \mathrm{PFU} \mathrm{mL}^{-1}$ (equivalent to $0.000336 \mathrm{HAU} / 50 \mu \mathrm{L} ; 1 \mathrm{HAU} / 50$ $\mu \mathrm{L} \approx 1 \times 10^{5} \mathrm{PFU} \mathrm{mL}^{-1}$ ) (Fig. $6 \mathrm{~B}$ ) and the assay confirmed the high selectivity as well (Fig. S7†).

Our proposed bioassay system was further applied for infectious bronchitis virus (IBV) detection in blood samples after confirming the successful binding of the CAu nanostructures and QDs with an IBV specific antibody (Fig. S8†). The chiroptical response of IBV detection was observed to be in the range of $10^{2}$ to $10^{4} \mathrm{EID} / 50 \mu \mathrm{L}$ with a limit of detection of $47.91 \mathrm{EID} / 50 \mu \mathrm{L}$ (equivalent to $0.00033537 \mathrm{HAU} / 50 \mu \mathrm{L}$ ) (Fig. 6C) and the assay confirmed the selectivity for only the target analytes (S9). Thus, the proposed chiral-based biosensor enables the utilization of this technique in reallife applications. 

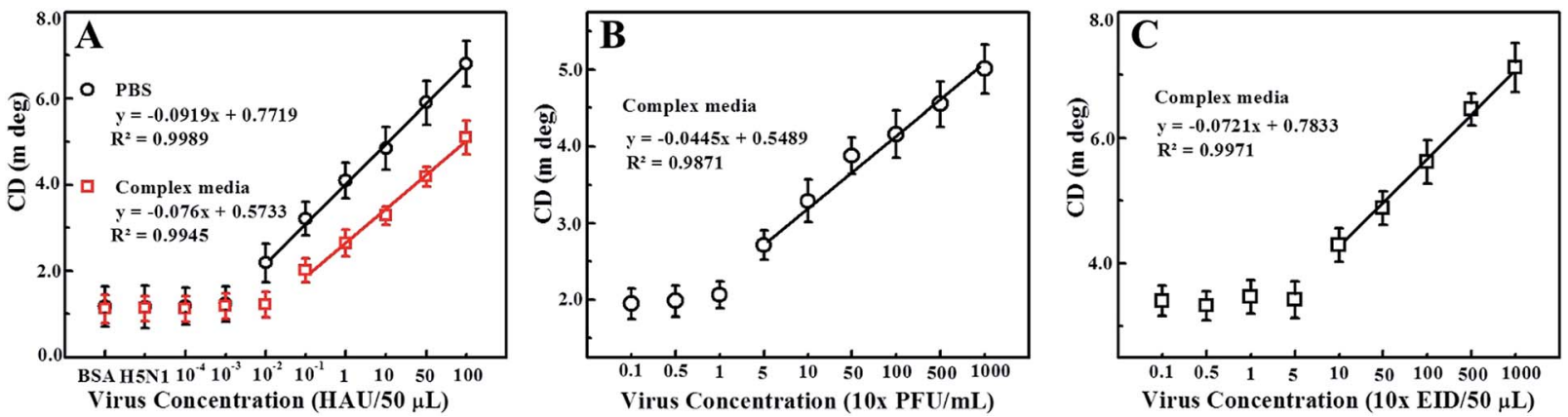

Fig. 6 Chiroimmunosensor detection of multiple virus culture samples. (A) Avian influenza virus A (H4N6); the closed circles (black) and squares (red) represent the sensing results of avian influenza virus A (H4N6) detection in PBS buffer and a complex matrix (chicken blood), respectively. (B) Fowl adenovirus (FADV) and (C) infectious bronchitis virus (IBV) detection in chicken blood media.

\section{Conclusions}

Chiral biosensors will be at the forefront of the bionanotechnology field in the near future due to their ultra-sensitivity and rapid response time. Our work demonstrates a framework and a method to achieve enhanced sensitivity using chiral metal nanoparticle-quantum dot nanocomposites for detecting bioanalytes in clinical samples. When the proposed sensing method was applied to colloidal CAu NPs and self-assembled CAu nanostructures, the latter showed better detection performance due to the multiple plasmonic scattering effects on the rough CAu nanostructures. Sensitivity at a pico-gram level was achieved, which is superior to the conventional ELISA methods, plasmonic biosensors and commercial kits. The sensing performance of the proposed method was also retained in complex biological media for avian influenza A (H4N6) virus, fowl adenovirus and coronavirus. The simplicity, and more importantly, the concept of optical rotation and energy coupling phenomena in the chiral plasmon-exciton systems may have academic significance, opening new doors for chiral bionanosensor development and further studies of chiro-optical memory, chiral catalysis, and light-emitting diodes.

\section{Conflicts of interest}

There are no conflicts to declare.

\section{Acknowledgements}

The authors sincerely thank the Natural Sciences and Engineering Research Council of Canada (400705) for funding this study. The authors thank Professor Rod Merrill of the Molecular and Cell Biology department of the University of Guelph for providing access to the circular dichroism equipment.

\section{Notes and references}

1 M. Achermann, J. Phys. Chem. Lett., 2010, 1, 2837-2843.

2 E. Cohen-Hoshen, G. W. Bryant, I. Pinkas, J. Sperling and I. Bar-Joseph, Nano Lett., 2012, 12, 4260-4426.
3 J. Lee, P. Hernandez, J. Lee, A. O. Govorov and N. A. Kotov, Nat. Mater., 2007, 6, 291-295.

4 F. Todisco, S. D'Agostino, M. Esposito, A. I. FernándezDomínguez, M. D. Giorgi, D. Ballarini, L. Dominici, I. Tarantini, M. Cuscuná, F. D. Sala, G. Gigli and D. Sanvitto, ACS Nano, 2015, 9, 9691-9699.

5 R. Jiang, B. Li, C. Fang and J. Wang, Adv. Mater., 2014, 26, 5274-5309.

6 Q. Zhang, L. Lee, J. B. Joo, F. Zaera and Y. Yin, Acc. Chem. Res., 2013, 46, 1816-1824.

7 V. K. Valev, J. J. Baumberg, C. Sibilia and T. Verbies, $A d v$. Mater., 2013, 25, 2517-2534.

8 M. H. Alizadeh and B. M. Reinhard, ACS Photonics, 2015, 2, 942-949.

9 Y. Zhao, A. A. E. Saleh and J. A. Dionne, ACS Photonics, 2016, 3, 304-309.

10 J. Butet, P. Brevet and O. J. F. Martin, ACS Nano, 2015, 9, 10545-10562.

11 M. Schäferling, X. Yin, N. Engheta and H. Giessen, ACS Photonics, 2014, 1, 530-537.

12 T. Hu, B. P. Isaacoff, J. H. Bahng, C. Hao, Y. Zhou, J. Zhu, X. Li, Z. Wang, S. Liu, C. Xu, J. S. Biteen and N. A. Kotov, Nano Lett., 2014, 14, 6799-6810.

13 W. Ma, H. Kuang, L. Wang, L. Xu, W. Chang, H. Zhang, M. Sun, Y. Zhu, Y. Zhao, L. Liu, C. Xu, S. Link and N. A. Kotov, Sci. Rep., 2013, 3, 1934.

14 X. Wu, L. Xu, L. Liu, W. Ma, H. Yin, H. Kuang, L. Wang, C. Xu and N. A. Kotov, J. Am. Chem. Soc., 2013, 135, 18629-18636.

15 Y. Zhao, L. Xu, W. Ma, L. Wang, H. Kuang, C. Xu and N. A. Kotov, Nano Lett., 2014, 14, 3908-3913.

16 X. Shen, A. Asenjo-Garcia, Q. Liu, Q. Jiang, F. J. G. D. Abajo, N. Liu and B. Ding, Nano Lett., 2013, 13, 2128-2133.

17 X. Lan, X. Lu, C. Shen, Y. Ke, W. Ni and Q. Wang, J. Am. Chem. Soc., 2015, 137, 457-462.

18 J. Cheng, G. L. Saux, J. Gao, T. Buffeteau, Y. Battie, P. Barois, V. Ponsinet, M. Delville, O. Ersen, E. Pouget and R. Oda, ACS Nano, 2017, 11, 3806-3818.

19 W. Chen, A. Bian, A. Agarwal, L. Liu, H. Shen, L. Wang, C. Xu and N. A. Kotov, Nano Lett., 2009, 9, 2153-2159.

20 A. J. Mastroianni, S. A. Claridge and A. P. Alivisatos, J. Am. Chem. Soc., 2009, 131, 8455-8459. 
21 A. Guerrero-Martínez, B. Auguié, J. L. Alonso-Gómez, Z. Džolić, S. Gómez-Graña, M. Žinić, M. M. Cid and L. M. Liz-Marzán, Angew. Chem., 2011, 123, 5613-5617.

22 Z. Fan and A. O. Govorov, Nano Lett., 2010, 10, 2580-2587.

23 J. Zho, S. Tang, J. Storhoff, S. Marla, Y. P. Bao, X. Wang, E. Y. Wong, V. Ragupathy, Z. Ye and I. K. Hewlett, $B M C$ Biotechnol., 2010, 10, 74.

24 J. Lum, R. Wang, K. Lassiter, B. Srinivasan, D. Abi-Ghanem, L. Berghman, B. Hargis, S. Tung, H. Lu and Y. Li, Biosens. Bioelectron., 2012, 38, 67-73.

25 S. W. Thor, H. Nguyen, A. Balish, A. N. Hoang, K. M. Gustin, P. T. Nhung, J. Jones, N. N. Thu, W. Davis, T. N. T. Ngoc, Y. Jang, K. Sleeman, J. Villanueva, J. Kile, L. V. Gubareva, S. Lindstrom, T. M. Tumpey, C. T. Davis and N. T. Long, PLoS One, 2015, 10, e0133867.

26 C. Li, D. Cao, Y. Kang, Y. Lin, R. Cui, D. Pang and H. Tang, Anal. Chem., 2016, 88, 4432-4439.

27 L. Deng, S. Sharif and É. Nagy, Clin. Vaccine Immunol., 2013, 20, 1189-1196.

28 H. Grgić, D. B. Hunter, P. Hunton and É. Nagy, Can. J. Vet. Res., 2008, 72, 403-410.
29 M. St Paul, N. Barjesteh, J. T. Brisbin, A. Villaneueva, L. R. Read, D. Hodgins, É. Nagy and S. Sharif, Viral Immunol., 2014, 27, 167-173.

30 H. S. Alexander, P. Huber, J. Cao, P. J. Krell and É. Nagy, J. Virol. Methods, 1998, 74, 9-14.

31 H. Grgić, D. B. Hunter, P. Hunton and É. Nagy, Can. J. Vet. Res., 2008, 72, 403-410.

32 J. J. Gelb, The American Association of Avian Pathologists, Kendall/Hunt Publ, Dubuque, Iowa, 4th edn, 1998, pp. 169-175.

33 L. J. Reed and H. Muench, Am. J. Hyg., 1938, 27, 493-497. 34 B. Xiao, S. K. Pradhan, K. C. Santiago, G. N. Rutherford and A. K. Pradhan, Sci. Rep., 2016, 6, 24385.

35 H. Yockell-Lelievre, F. Lussier and J. Masson, J. Phys. Chem. $C, 2015,119,28577-28585$.

36 Y. Yang, S. Matsubara, M. Nogami, J. Shi and W. Huang, Nanotechnology, 2006, 17, 2821-2827.

37 W. W. Yu, L. Qu, W. Guo and X. Peng, Chem. Mater., 2003, 15, 2854-2860.

38 R. Wang, J. Lin, J. K. Lassiter, B. Srinivasan, L. Lin, H. Lu, S. Tung, B. Hargis, W. Bottje, L. Berghman and Y. Li, J. Virol. Methods, 2011, 178, 52-58. 